the segment.
These findings indicate that teachers wanted to use the segments in the ways
that were compatible with their teaching that were compatible with their teaching
style and the interest and needs of their style and the interest and needs of the have a resource which could be adapted to their particular style and not
ed a format of usage.

Student results

All the classes involved in the study test on the various tests used (See Table I). Complete tests results are available another paper (Lewis, 1981). The priman students had a pre test score of $1.17 \mathrm{com}-$ pared to a post teeth, hair, shoulders, feet, hands, ears, eyes and neck in French as a result of the program and its associated activities.

The grade one level pre test score was 2.55 while the post test score was 7.09. for nose, mouth, teeth, hair, shoulders, feet, hands, ears and eyes and neck between the pre and post tests.

Another grade one sample scored 1.19 on the pre test and 5.0 on the post test. for hands, feet, neck, teeth, hair and eyes between the pre and post tests. At the grade two level studan another est on fruits and vegetables. The students did significantly better on both post tests. learned the French words for orange, banana, apple, potato, lemon, onion, grapes, carrot, tomato, pineapple, peach, and corn between the pre and post tests. In terms of body parts the students learnhair, teeth and eyes between the pre and post tests.

At the grade three level the students also had two tests; one on body parts and one on fruits and vegetables. In both cases the post test score was significantly three students learned the words for ears, mouth, nose, hands, feet, hair, teeth, eyes and neck over the duration of the project. In terms of fruits and vegetables the students learned the words for orange, cherry, banana, apple, grape and carro

The grade five students had a test based on articles of clothing. On the pre test none of the students knew the words for shoes, shirt, pants and socks. However, by the end the students had learned the words for socks, shoes, shirt and pants. There were significant gains on all the articles of clothing. At the grade six leve the articles of clothing test was also given. At this level some of the students an the grade fives did. Nevertheless, the post of how much the students learned. The for shoes, shirt, pants and socks as a result of the experiment.

Teacher use and enthusiasm

One of the most exciting aspects of the project was the enthusiasm exhibited by
the participating teachers. In two cases,

teachers managed to exert enough

pressure on their schools and the school board to purchase additional videotape
units. During the project itself, teachers units. During the project itself, teachers
continually demonstrated their interest and enthusiasm in the project and what it was doing for their schools. Often, the mal effort required to teach a class using the videotape units in the classroom. During the project, there was no need to encourage teachers to do the tasks required of interest in performing their required work. In all cases, the teachers wanted more information and more of the proossibly be provided during the year.

Curriculum integration One of the strengths of the project was have to completely focus on learning and teaching of French. It was just as easy to include a segment dealing with social
studies, health or personal development along with segments on French. During the study, teachers included segments to reinforce areas of interest. As a result French was integrated into othe classroom activities. 1n this matter, televing aids

\begin{tabular}{llccccc}
\multicolumn{5}{c}{ Table I } \\
Grade & Pre and Post Test Means for all Grades \\
\hline & Test & Pre Test & Post Test & T-Score df \\
\hline Primary & & Mean & Mean & & \\
Grade One (1) & Body Parts & 1.17 & 3.90 & $6.34^{*}$ & 29 \\
Grade One (2) & Body Parts & 2.55 & 7.09 & $7.29^{*}$ & 21 \\
Grade Two & Body Parts & 1.19 & 5.00 & $8.46^{*}$ & 20 \\
& Body Parts & 2.88 & 5.44 & $5.45^{*}$ & 24 \\
Grade Three & Fruits \& Vegetables & 1.36 & 6.80 & $11.50^{*}$ & 24 \\
& Body Parts & 1.19 & 6.75 & $7.50^{*}$ & 15 \\
Grade Five & Fruits \& Vegetables & 0.13 & 4.19 & $6.83^{*}$ & 15 \\
Grade Six & Clothing & 0.00 & 2.50 & $8.50^{*}$ & 17 \\
& Clothing & 0.59 & 2.65 & $6.80^{*}$ & 16 \\
& & & & ${ }^{*} \mathrm{p}>.05$ \\
& & & & & & \\
\hline
\end{tabular}
to teachers and students as earning French. As the program con number of different approaches and subgram. As a result, students and teach could have a wide range of subject matprogram. Although testing would be much more difficult, it is thus possible

Implications

The study demonstrated that teachers which were directly suited to their needs. However, the available segments still did Long term success of the segment ap-
Lersers proach for television means that a wide
range of segments need to be made accessible to teachers. Most provincia copies of telelvision programs they have province usually for the price of a blan cassette. Segments of these television pro-
grams could easily be integrated into the type of program described in the study. ther, it would be possible for groups of segments on particular aspects of thei teaching. These segments could then be exchanged by teachers similar topics so The teacher resource centre of the Halifax city schools has proposed a system to
teach teachers to produce one minute teaching segments which could then be housed in the library and used as the need there could be a wide range of segment

In addition

列 ce short instructional segments thu paching them the skills of visual literacy nal material for the classroom. The segment approach has proven its sefulness in children's television proStreet, The Electric Company followed. Passe Partout, a French language program for francophones uses the seg. mention to the students. It is possible the that the segment technique is widely applicable in the education system. The segment technique will also be
enhanced when videodiscs become
available. Videodisc technology will vailable. Videodisc technology wi
llow a teacher to access any segment in allow a teacher to access any segment in replay and immediate access will be The study has demonstrated the need lor wider testing of the concept of segment type television programs. Expan-
sion will allow many more questions regarding the use of segments in educ ional applications to be discussed.
ins

REFERENCES

Ball, S. and Bogatz, G. A. The first year of Street: An evaluation.
Princetown, N.J: Educational Testing Service, 1970.

oogatz, G.A. and Ball, S. The second year of Sesame Street: A continuing evalua-
tion. Volume 1. Princetown, N.J.: Educational Testing Service, 1971a. of Sesame Street: A continuing evaluation. Volume 2. Princetown, N.J.
Educational Testing Service, 1971b.

ouchard, Andre. Immediate feedback seven, evaluation of 1979 segments. Research Report Les Com-

政 cellence in tol at the service of exmanuscript, $1980 \mathrm{~b}$.

hin, R. and Downey, L. Changing change: innovating a discipline. Secoaching, Washington, D.C.: American Educational Research Association, 1973.

eming, W.G. Evaluation of four educa-

tional television program series produc-

ed by the Ontario Educational ComNu oldberg, M. and Gorn, G. Television's impact on references for non-white inserts. Journal of Broadcasting. 1979, 23(1), 27-32.

eroux, L. and Goldberg, M. "A survey of childrens motivational effects and comments." Research report McGill University Faculty of Management May, 1980

Lamerand, R. and Tracy, P. Acceptance
by the classroom teacher of television by the classroom teacher of television ing. Researched report, Ontario Institute for Studies in Education, 1976. Laosa, Luis, M. Formative research and evaluation in the application of televi-
sion media to bilingual/multicultural sion media to bilingual/multicultural Educational Research, 1975, 25(5), 302-309.

Lewis, R.F. and Fisher, G. An evaluation of the junior high school series "Vive la

\title{
Can Technology Revive This Classroom Simulation Update: Seldom Used Instructional Technique?
}

By Walt Buehning \& Erv Schieman Development of the Current Project

The Learning Technology Unit in the
Faculty of Education at the University of Calgary, over an eight year period, has

Talt Buehning is a Professor of $M u$ ic at

the University of Calgary.

Erv Schieman is a Senior Instructor in University of Calgary. developing a variety of experimental in-
structional simulators. As well, varying structional simulators. As well, varying
designs for software formats and configurations have been tried with the materials experiencing a wide range of ef-
fectiveness. While many problems still exist, the experimenters have gained a great deal of experience and have
developed expertise in an instructional technique which has yet to be exploited many trials utilizing the experimenta simulation packages, the intent of the in vestigators has been to demonstrate that stitute of Education. Technical report, ewis, Richard $F$ An evaluation of Allons-Y" Hallfax, NS: Atlantic Institute of Education. Technical report, Lewis, Richard F. Sesame Street goes stitute of Education, Technical Report, almer, E.L. Formative research in the production of television for children. the National Society for the Study of Education. Chicago Illinois: National Society for the Study of Education, Williams, F., Van Wart, G. and Stanford, M. National evaluation of a Spanish/ Austin, Texas: Center for Conmunicat ion Research, University of Texas, 1973.

MTEC ideas booklet in the works AMTEC is in the prot in the works are to be practical in nature and will focus upon using media in instruction. It is envisoned that each booklet will be written from a personal point of view, with emA theoretical. Anyone interested in sharing their ideas hould send manuscripits covering the ow, when, where, why and what of from 1-10 pages.

Ther and/or inquiries should be Resource Center Co-ordinator School District \#34 (Abbotsford Abbotsford BC V2S 3P5
作 the area of inter-persor professionals, ion and problem solving strategies. When targeted for teacher training pro$d_{\text {, can }}$ provide instruction in the mos roblematic area in schools today, name In the current project, a design team, in personnel, design/development specialists nd evaluators has developed three prototype instructional packages intended 
for use in methodology courses. This current project seeks to not only develop
materials but also to test the efficacy of the overall design strategy and the updated hardware configuration.
By means of the microcomputer, which By means of the microcomputer, which
permits the accessing of any one of a ts of videotape, visual can be presented in any sequence to
students. The participants in the simulation can react and respond to occurrences which require decisions and see probable
follow-up consequences of their decisions. In the prototypes which have been
developed, the following events typically 1. A videotaped incident, usually a commonly occuring yet important classroom event, is presented. The making point, leaving the student in a position where some action must be forthcoming.

2. Up to five alternative action choices are presented on the CRT. These courses of action open to the teacher.

3. The student makes his/her decision and enters it into the microcomputer
through the keyboard. The appropriate follow-up sequence is located depicts a rational outcomse ideally also lead to further critical incidents. The three simulation packages develop-
ed and tested by the members of the team were Counselling Procedures, Classroom
Communications and a Musical Critical Incident Simulation.

was intended to train the student to deal with the following issues:

1. coping with the silent client

2. racilitating client self-disclosure

3. coping with the reluctant clie
4. using open-ended questions expression of affect.

Dr. S. Mandaglio, content specialist for the Counselling Procedures Simulation observed that the simulator technology
had two advantages over other available curricular aids. The first advantage of the system is that the student/counsellor is an problems demanding some decision, and immediately sees the probable conse-
quence of his choice. The second advantage is that the student becomes painfully going interview is strongly counsellor's actions and response. Other currently available aids lack these important advantages.

lation the second Communications Simustrated and reinforced classroom pro-
cedures that helped the participant with tudent control. The objectives for these 1. leadership stances:

standing, sitting, moving 2. presenting strategies, e.g. voice, nonverbal support, questioning . controlling strategies such as eye

4. maintenance of routine learning conbuting materials, grouping, etc.

5. verbal interaction, e.g. recognizing,
reinforcing, accepting ideas and feelings.

6. varied teaching strategies.
The content specialist for the Classroom Communications Stimulation, Dr. G. Miller, observed that a major benefit
of this type of simulation is in diagnosing and altering response behavior develop ment. Another benefit appears to be the teachers to internalize a more dynamic eadership role in the classroom. The Music Education Simulation, the specialist, Dr. W. Buehning, could have been titled the Critical Incident Simulamaterials. As used in this study, the incident is a common problem that teachers
deem critical to the success of the teacher candidate. This aspect of teacher educaion was pursued because of the following assumptions:

Incidents in teaching are critical to a teacher's success are not usually en-
countered in regular practicum experiences. 2. It is impossible to provide certain experiences in a classroom without
disrupting the progress of the class. 3. Video simulation provides an opportunity for a future teacher to
vicariously interact in a conflict vicariously interact in a conflict
situation without negative consequences to a relationship.

4. Future teachers can be given a dramatic warning of likely incidents and an opportunity to reflect on
their reactions through the use of video simulations.

5. Reactions to potential problems can vironment such as video simulation. . Classroom management and control in music courses are different than in other subject areas because the ac-
tivities and responsibilities are different.

7. Performance and academically oriented music classes make different demands on both student and teacher, (Schieman, 1982).
It is possible to justify

It is possible to justify subjecting the
students to common classroom problems d" and to assume that having considered the causes of the incident and the possible consequences, the student would be less
likely to make unreasoned responses real teaching role. The aims of the critica ident simulation are:

Students will experience incidents
that have been deemed critical from

a survey of teachers.

dents will reflect on their vicar ous experiences and develop a range 3. Students will practice

responses to the critical incidents, at
least within the range included in each simulation

make some responss factors which preferable to others.

The student's future teaching will be enhanced by the poise and respect
gained because of his increased ability to make acceptable responses

More acceptable response will

future lower the anxiety of the teacher's classroom and free time
and energy for facilitating learning chieman, 1982).

At present the students in the Music study the book T.E.T. Teacher Effectiveness Training by Dr. Thomas Gor.
don. A problem is dealt with differently it don. A problem is dealt with differently if is strictly a student problem. The latter is approached in a non-directive way, atapproached in a non-directive way, at
tempting to show empathy and to allow the student to develop to his own solution. After discussing traditional ineffec-
tive confrontations and the improvement tive confrontations and the improvement
of the environment, Dr. Gordon presents a six step directive problem-solving probecome so disruptive that they are what he calls teacher owned. In the University of Calgary classes, some mini-lectures
and discussions over the book occur during the regular classes but the University students are expected to demonstrate their understanding of the principles in practicum programme held on the cam pus one evening a week.

be an improvement over the seems to less directive problem-solving procedure. If the interaction with the video material is at all effective, and it seems to be, then the materials must be psychologically sound and carefully tested before being student teaching.

The designers in all three components question of how the student's responses could be improved through the exgiven a simple problem-solving model to guide their thought processes. The model is a triangle with the points representing
information gathering, hypothesis forma-

VOLUME 13, NUMBER 1, 1984 ion and hypothesis testing. When atmpting to solve a problem, a perso
moves from one point to either of the others. There is no definite sequence or
restriction in the number of moves. Further number of moves. Furframework can be found in Buehning's dssertation, (Buehning, 1971).

information gathering

hypothesis
formation
testing

Rationale

The ability to work with people education, but it is one of the most impormiversity professors whose responsibili-
$y$ it is to prepare educational practitoners, it remains an important challeng oo often this aspect of a stu-
ent's education has been left to chance to the cooperating teacher to teach dur ing the formal practicum experience. In
istening to young teachers discuss what ey learned during their first two year as a regular teacher, it is apparent that th
skill of working with other students, parents and administrators is often inefctively taught at the university. Knowecessarily provide the teacher with the necessarily provide the teacher with the
ability to perform in a satisfactory manner. This may be one of the reasons so many young teachers abandon their he University of Calgary under the leadership of Dr. Erv Schieman decided
that something unique could and should be done about this obvious deficiency. Though a simulation facility existed on campus, it was outdated. Several recent changes in this facility have made it
technologically current, therefore it wa technologically current, therefore it was one of the most promising alternatives
considered for the project. Unfortunately the results of the early research utilizing couraging. A study of the materials used in that early research provided some
clues. "The original theoretical basis for clues. "The original theoretical basis for
the technique was based on the operant

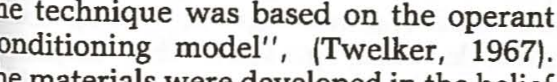
that behavior was controlled by the environment and reflected this psychological orientation. Although later accepting
the model of "the teacher as an informa the model of "the teacher as an informa-
tion processing system which receives in formation, evaluates, makes decisions encodes messages for the student, and transmits the message using appropriate communication channels" (Twelker, 1967), the materials were not changed to
reflect this revised view of the role of the

CANADIAN JOURNAL OF EDUCATIONA eacher. In addition the filmed sequences he simulator was limited in the number and frequency of responses, detracting rrom

The effect of the classroom classroom simulator teraction between the student and the operator resembled a tutorial and the
judgements of the operator had an in. judgements of the operator had an inexplaining why "no significant dif-
ence on the ference" findings were so common. In spite of the weakness, one study found that the simulation experience was "at least as valuable as the first two weeks of
student teaching", (Cruickshank and student teaching" " (Cruickshank and
Broadbent, 1968). "Principles which can can be developed through plabsroms simulator experience prior to the teachertrainee's student teaching experienc (Vlcek, 1965), and that these principles do transfer to the student teaching extrainee confidence in ability to teach is in creased through classroom simulator experience", (Vlcek, 1965).

Instructional Objectives the area of classroom management is the over-all objective of the use of simulation in instructing student teachers. Add-

- the field testing of the prot

simulation materials to determine the effectiveness in increasing the
student's awareness to crisis mangement in the classroom.

to assess the potential of this instructional strategy in the area of in especially those dealing with teacherstudent relationships.

field test the simulator with a different computer/video player inter-
face which has greater search ac al computer

\section{Equipment}

field tested at the present time includes an Apple II Plus $48 \mathrm{~K}$ microcomputer with Sony SLO-320 Betamax video record player play combination. A variation of resolution black and white video monito for displaying computer text and a larg screen video projector for more life-like fully-branching programmes limitily of by the available space on the videotape and floppy dis.

The Apple II Plus microcomputer wa L COMMUNICATION

availability and its outstanding track high level programming language, Applesoft Basic, which closely resembles writ
ten English, was a factor for its selection. The computer programming had to be ind First it wree major concens in mind. First, was matended that the smulation experience. Second the system had to supply the
capability for the learner to randomly ac作 materials with a precise degree of evaluation of Finally, the requirement for delivery system had to be addressed. The mpact of the content and the delivery delivery could only be measured with the delivery system possessing the capability and elapsed time in making decisions, which could then be retrieved at the discretion of the evaluators.

Methodology

A series of trials were initiated in the spring and fall of 1981 to check the and also to check the simulation logic along with the appropriateness of video ext. As well, the various measurement nstruments and user's guides were valiuestionnaires were designed to collect thestionjaires were designed to collect the programme materials. Of interest to the investigators were such aspects as reaction to the delivery system, appropri-
teness of critical incidents used, interest nd motivation of the participants and the sope of the behaviors included in the
software. Following the initial trials a formative whether subjects developed a repetoire of rategies in dealing with the problem 
CLASSROOM SIMULATION ed from page 9

to the individual participants posed by the technology would probably force the training prior to complete involvement in the simulation experience. After analysis there was no evidence that the simulations increased the actual number of alternative solutions to a problem that a some indication that subject analytical and selective in their instructional decision-making after participating in the stimulation.

Summary

It must be kept in mind that the nature of the simulations dealt with in our pro-
ject were such that the effects of the simulation would be expe future time. As well, in all of the simulated incidents, the occurrence of conditions that would call for individuals to use what they have learned via the
simulation is unpredictable. It highly impractical for investigators to go through weeks of observation to have a classroom incident occur which parallels the simulation and then assess whether Therefore the evaluation of the simula tion materials could not practically be carried out by direct observation. The lecting judgements by a cross-section of users. They were asked to rate various statements on a 5-point Likert-type scale. which was collected and while conclusions as a result are difficult to arrive at, the exercise was a tremendous value to the project team and the participants. What proct has can be used to develop and to deliver in struction in the area of teacher training. What is required now is additional research and further refinement of the methodology so that teacher training propotential.

\section{REFERENCES}

1. Buehning, Walter P., "Critical Incidents and Their Use in the Educ tion of Music Teachers." UnpublishUniversity of Oregon, 1971.

2. Cruickshank, D.R. and Broadbent .W., An Investigation to Dete ing on Student Teaching Behavior cited by Paul A. Twelker, Instructional Simulation Systems, Corvallis, Oregon: Continuing Education Pub-
Schieman, E., Simulation Program for the Training of Teachers. Un( ble from Alberta Advanced Education and Manpower, Learning Systion and Teacher Preparation."

School Review, 75, (Summer, 1967) COMPUTER NEWS Vlcek, C.W. "Assessing the Effect and Transfer Value of a Classroom Sim D. Thublished D. Thesis, Michigan State U.

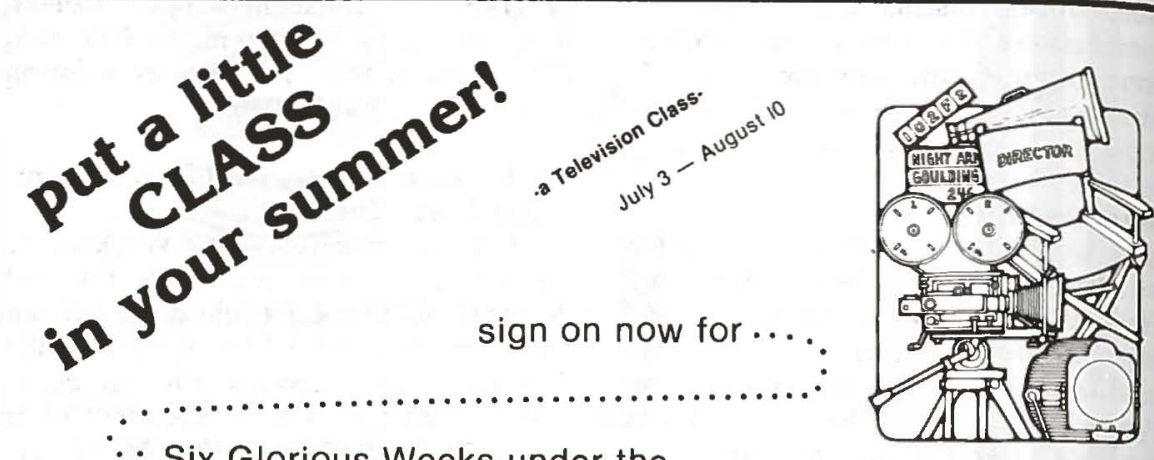

Six Glorious Weeks under the lights, behind the scenes, and in Research and Application. Editing Resion I

\section{ED MDA 481/483}

Another class available for three weeks:
Introduction to Educational Media and Instructional Technology
ED MDA 35

Registration DEADLINE April 2, 1984

WRITE

EDUCATIONAL MEDIA Depl. or Secondary Education
University of Alberl
EDMOONT

\section{Board of Directors 1983-84}

Past President

Mr. Tom Rich

Department of Education

P.O. Box 200

Charlottetown, P.E.I. C1A 7N8

President

Dr. Barry Brown
Head, Department of Educational

Communications

University of Saskatchewa

Saskatoon, Saskatchewan S7N oW0

President-Elect

Supervisor of Instructional Materials

Calgary Board of Education

3610 - 9th Street S.E.

Secretary/Treasurer

Mr. Ron Eyre

Educational Media Consultant

Wellington County Board of Educatio

Torth Guelph, Ontario N1E 6K2

Computer Museum Board. Director of Instructional Media Vancouver Community Colleg 1155 East Broadway Vancouver, B.C. V5T 4N4

Board Member Ms. Danielle Fortosky University of Saskatchewan Saskatoon, Saskatchewan S7N 0W0 Board Member Ms. Judy Benson Saskatchewan Continuing Branch 1855 Victoria Avenue
Regina, Saskatchewan S4P 3V5

Editor: Canadian Journal of Educational Communication Dr. Denis Hlynka Faculty of Education University of Manitoba
Winnipeg, Manitoba R3T 2N2

Procedure
COMPUTEd from page 3

$\$ 100,000$ to $\$ 1,000,000$. Schools ca receive roughly one program per 5 Ap recommendations, but schools can pick from the entire SVS catalogue.

Canadian schools should send schoo name, address, district, number and type of computers in use, contact person,
phone number and comments to: TC Data 2142 Trans Canada Hwy., Quebe H9P 2N4. Telephone: (514) 683-7161.

The Computer Museum is located at One Iron Way, Marlboro, Maryland, Computers from Stretch (the IBM 7030) to ILLIAC IV, the world's largest com puter recently deinstalled from NASA the Four Generations of Computing
showing the evolution from the era of showing the evolution from the era of
vacuum tubes to the microprocessor; and parts of the ENIAC, EDSAC and the
Whirlwind. Also on display are early calculating devices, the first transistorizJacquard loon.

Museum services include a lectur museum store, a quarterly tours, library and viewing room and an inter program. The museum is open Monday through Friday, 1:00 p.m. to 6:00 p.m. (617) 467-4036. CTW Introduces Children's Com-

The Children's Television Workshop is publishing a new magazine this fall puters and the new electronic technologThe magazine, called ENTER, will be the first created by CTW independent of an educational television series. It will also be the first CTW magazine to accept advertising of products and services by tion of card computing starting with the and software companies and by educa- tional publishers - in order to provide dience in this case) with new product Editorial content will include career opportunities and issues relating to the $80^{\prime} \mathrm{s}$. Fo computer technology in the ents in computer technology, career awareness profiles profiles of a wide range of professions, things with computers and video games, "how-to" articles, consumer awareness some simple programming challenges. An isual subscription price for ENTER's 10 issues will be $\$ 12.95$ U.S. Single issues rate for teachers will also be offered. consumers the $10-16$ year old target aufeatures, games, quizzes and puzzles, and

\section{AMTEC ANNUAL ELECTIONS}

The positions are

1. Vice-President (President-Elect) This is a three year term, beginning in June, 1984 at the Annual Conference. There will be one year as Vice-President, one year as President and one year as Immediate Past President.

2. Member-at-Large

This is a three year term beginning at the Annual Conference in June, 1984,

1. If you wish to nominate someone:

Nominations may be made by any five AMTEC Members providing the nominee is a member of AMTEC and has signified his/her willingness in writing. A brief biographical sketch of the nominee must be sent to the Chairman of the Nominating Committee along with the nomination.

2. If you wish to be nominated:

Indicate this to five AMTEC members who will arrange to nominate you by sending a letter of their intention and your biographical sketch to the Chairman of the Nominating Committee. You must be a member of AMTEC.

All nominations must be received by the Chairman of the Nominating Committee by January 30, 1984. Send nominations to: Tom Rich

\section{Chairman Nominating Committee}

Past President, AMTEC

Director, Educational Services

P.E.I. Dept. of Education

Box 2000

Charlottetown, P.E.I. C1A 7N8 